
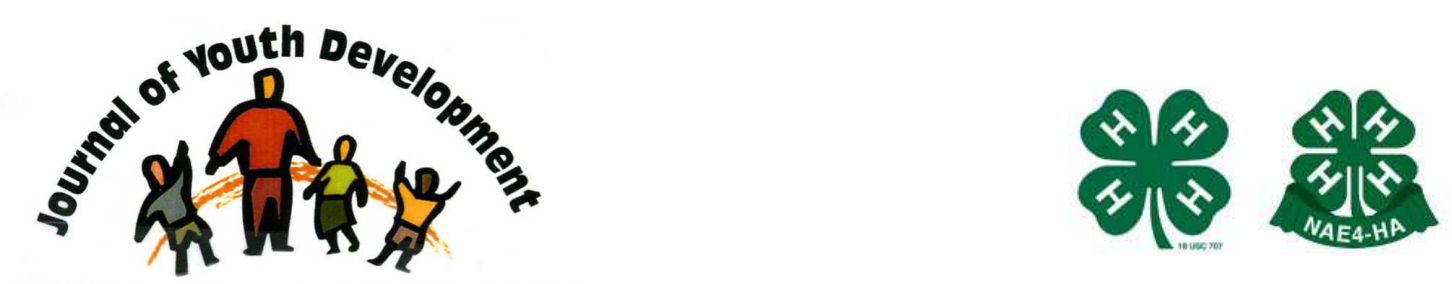

Bridging Research \& Practice

\title{
Self-Esteem and Feelings of Community Connectedness of At-Risk Adolescents Attending Community-Based Afterschool Programs
}

\author{
Tina Loughlin \\ University of Florida \\ Gainesville, FL \\ loughlin.tina@gmail.com \\ Rosemary V. Barnett \\ Department of Family, Youth, and Community Sciences \\ University of Florida \\ Gainesville, FL \\ rbarnet@ufl.edu \\ Gerald R. Culen \\ Department of Family, Youth, and Community Sciences \\ University of Florida \\ Gainesville, FL \\ grculen@ufl.edu \\ Nicole L. P. Stedman \\ Department of Agricultural Education and Communication \\ University of Florida \\ Gainesville, FL \\ nstedman@ufl.edu \\ Caroline Payne-Purvis \\ Department of Family, Youth, and Community Sciences \\ University of Florida \\ Gainesville, FL \\ cmpayne@ufl.edu
}




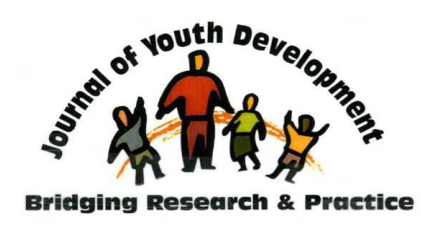

\section{JOURNAL OF YOUTH DEVELOPMENT \\ bridging research and practice}

\footnotetext{
Volume 8, Number 1, Spring 2013

Volume 8, Number 1 , Spring 2013 Article 130801RS001

Article 130801RS001
}

\title{
Self-Esteem and Feelings of Community Connectedness of At-Risk Adolescents Attending Community-Based Afterschool Programs
}

\author{
Tina Loughlin, Rosemary V. Barnett, Gerald R. Culen, Nicole L. P. Stedman and \\ Caroline Payne-Purvis \\ University of Florida
}

\begin{abstract}
This research investigated the relationship between adolescent afterschool program attendance, self-esteem and feelings of community connectedness. Thirty-nine of the 61 at-risk adolescents enrolled in two federally funded, community based afterschool programs participated in the study. Participants completed a 10-item self-esteem questionnaire and a 5-item section of the Youth Involved in Community Issues Survey (YICI) to measure perceptions of community connectedness. Attendance records were also collected from the sites. Data were analyzed using Pearson Correlations.

Results indicated that there was not a significant relationship between the total variables. The individual item analysis, however, did find a significant relationship between adolescent community connectedness and self esteem items. Findings suggest that there is a relationship to be explored and strengthened through means of community outreach for adolescents.

Conclusions from this study have important implications for youth practice. Specifically, program leaders need to help adolescents get involved in the community as contributing members.
\end{abstract}

\section{Introduction}

"Self-esteem is defined as a person's overall sense of worth and well-being" (Arnett, 2010) and is an integral part of youth development. It is important that adolescents develop a high selfesteem from an early age and continue it into their adult lives. There are many factors that contribute to adolescent self-esteem, including: personal identity, personal achievements, family, friends, school, neighborhood, and community. Since adolescence is the period during which identity issues are most prominent and most crucial to development, Erickson (1950) stated that it is important that youth are able to establish a clear identity. Identity serves as a 
basis for initial commitments in adult life and as a foundation for later stages of development (Arnett, 2010). Self-esteem in adolescence can fluctuate as youth are striving to find their identity. Through positive youth development programs, however, a youth's self-esteem can be strengthened, thus, allowing them to feel better about themselves, their identities, their families, friends, and the community in which they live. "While many techniques have been used to enhance adolescent self-esteem, afterschool program attendance and the opportunity to connect with the community can have a significant effect on the self-esteem of a youth who participates" (Saunders-Ferguson, Barnett, Culen \& TenBroeck, 2008).

The use of one single approach can be difficult when trying to help diverse groups of adolescents, thus, communities, families, and schools must create opportunities for the youth to thrive in the environment in which they live, grow, go to school, and play. Afterschool programs and the chance to connect to communities through volunteer work provide youth with an outlet, a place to exhibit their strengths and gain a feeling of belonging and connectedness to their community (Barton, Watkins, \& Jarjoura, 1997; Benson, 1998; Broadbent, \& Papadopoulos, 2010); Halpern, 2005; O’Donnel, Michalak, \& Ames, 1997; Schine, 1990; Ybrandt, \& Armelius, 2008 Ref. says 2006.

\section{Current Practices}

In adolescence, the middle and high school years are a time when many lifestyle changes are made. This can prove to be extremely difficult for adolescents in terms of their evolving selfesteem. This period brings change that is unfamiliar and often unwelcomed by adolescents that must adapt and overcome the unfamiliarity that has suddenly been thrust upon them. During the years of middle and high school, it is imperative that these changes be examined in efforts to help promote positive development in a time of such turmoil.

This literature review examines self-esteem of inner-city adolescents who felt connected to their communities through afterschool and community program involvement. The first section examines the self-esteem of youth who are involved in after-school programs in order to define the need for such programs and show the benefits that are incurred by the adolescents. This section examines afterschool programs that are in place and functioning in a manner that is beneficial to adolescents attending the program. The second section discusses community connectedness and how youth involved feel about the accomplishments and friendships they have made in the communities in which they live. It also examines the positive outcomes of programs that have encouraged youth to get involved in the local community as a means of building resilience.

\section{Inner City Youth, Self-Esteem and Afterschool Programs}

Adolescent self-esteem, behavioral and emotional status, and social context, including the peer group, family, and school social system, all play a role in adolescent aggressive behaviors. The unsupervised hours of the afternoon are a crucial time for adolescents. It is during these hours that adolescents tend to get in the most trouble simply because they have nothing to do. In a study conducted through a partnership with the local YMCA, three elementary, middle and high schools, 54 middle and high school students from low-income areas who were at high risk for behavioral problems were taken to mentor 584 elementary school-aged children during the afterschool hours (O'Donnell, et al., 1997). The teen mentors went through an intensive training process in order to qualify and were supervised at elementary schools. The aim was that the program be preventative and keep the teens off the streets, thus, services were 
provided for both the mentors and the mentees who participated. Through the afterschool program, both the mentors and mentees benefited from a bonding experience that heightened the self-esteem of all involved. In fact, $89 \%$ of the mentors reported positive changes in themselves due to the employment opportunity. The program also gave the younger youth a safe place to go after school, helped them build a positive self worth, and provided childcare for their parents. Overall, the program had positive effects on the youth, their families, and the community.

Inner-city youth programs operate with the aim to address the normative tasks of adolescents without neglecting the range of vulnerabilities like self-doubt and mistrust of others (Halpern, 2005). Adults have an important role to play in youth development and are essential for teaching developmental tasks. Many students have low self-efficacy and get lost in the hustle and bustle of large urban high schools, thus, afterschool programs are needed to help show these at risk students how to be good citizens. An afterschool program is a place where students can go and get extra support they need due to the deficit they are receiving at home or in school. Through the afterschool program, students will try out different roles, sample different kinds of experiences, question themselves and others, take risks and test limits. In order to service these children effectively, it requires a variety of persons and social resources as well as the youth being open to new experiences and willing to take the steps necessary to be able to succeed. Many of the youth suffer problems rooted in earlier life experiences such as loss of a family member, absentee/erratic parents, early pregnancy, dropping out of school, responsibility for younger siblings, pressure from gangs, contact with police, juvenile justice, and child welfare authorities (Halpern, 2005). The afterschool program provides a place for those that fall somewhere between school stars and the disconnected due to negative effects during their adolescence. Thus, afterschool youth programs need to create conditions for reworking as well as for developing self-hood (Halpern, 2005).

\section{Positive Youth Development and Community Connectedness}

Youth often have the opportunity to make a huge impact on the community and neighborhood in which they live. Communities also can help make the youth development process go as smoothly as possible by providing programs for youth to participate in that make them feel connected to their community and want to give back to it. High feelings of community connectedness have been proven to help adolescents with positive development. Community connectedness has also been found to act as a mediator for adolescents who have depressed or suicidal tendencies (Matlin, Molock, \& Tebes, 2011).

Adolescents who tutor their peers or younger children, visit the aging, assist shut-ins, participate in programs to educate their communities about substance abuse, organize an action campaign to rehabilitate a building, improve a playground, clean up a stream, or advocate for the homeless are filling the void that our age of technology and alienation has created in their lives. Perhaps in more positive ways than their counterparts of an earlier era, they are assuming meaningful roles and responding to real needs of their society, as well as to their need to be needed (Schine, 1990). This participation in community development allows youth to obtain a feeling of belonging and contributing that sustains them even when the work is difficult or dull. For young people to learn most effectively from their participation in community service, however, they must have opportunities to reflect thoughtfully upon the meaning of their work. A youth's desire to reach out to adults other than parents and teachers, a drive to test values, and an opportunity to try on new roles, are all important developments during the period of adolescence. Most, if not all, young adolescents will derive benefits from 
engaging in meaningful service to their community. Working with the very young or the aging, young volunteers enjoy the warm welcome and affection that greet them, and at the same time, their self-esteem is bolstered by the knowledge that they are valued and do, indeed, "make a difference" (Schine, 1990).

Many after school programs, such as the YMCA and Boys and Girls Club of America, offer youth volunteer opportunities that are often more appealing than those provided by schools, as youth do not feel restricted by the school schedule and are more able to do the kind of volunteer work that they really want to do. Establishing community service as an integral part of the program in middle level schools, however, can constitute an important first step in true reform. The challenge is to create environments and opportunities that will allow those qualities to develop, "to nurture young people in their initial quest toward an effective and satisfying adulthood" (Hornbeck, 1988). This community service policy identified the importance of community involvement in key decisions about schooling. One model aimed to promote self-confidence and self-esteem, develop life and problem solving skills, encourage the practicing of social skills, link youth into appropriate community services, and ultimately, facilitate engagement in education. This model is beneficial to all involved. The community receives a volunteer, the youth's selfesteem is bolstered, and the school has fostered change in a young person.

Broadbent and Papadopoulos (2010) found that six in ten youth believed, as a consequence of participating, that they were now confident and they valued highly the experience of exploring and learning in their local communities. They also enjoyed engaging with diverse people, whether as a volunteer, assisting others, or engaging in new experiential learning and skill development. The program also improved the overall school performance of five out of ten youth. Learning can happen at home and in neighborhoods as well as at school--wherever young people with curious minds spend time. Thus, in schools that provide high quality teaching and an array of experiences and skill-building opportunities in a variety of community environments, learning is deepened and strengthened. Clearly, communities need to be environments where young people can avail themselves of such opportunities and it requires that communities, programs and governments work together in order to achieve long-term sustainable program outcomes and benefits (Broadbent, \& Papadopoulos, 2010).

Local schools can also benefit from community centers as they may provide youth with anger problems and other disabilities with a place to let out their frustrations, whether it is by playing on a sports team or just interacting with other youth who are similar to them. The centers provide a place for cooperative learning and are a great resource to schools. The centers allow schools to focus on educating youth, rather than trying to fix their problems while educating them. The center ultimately can provide a support system for youth to develop skills and competencies; provide youth with opportunities to practice new behaviors and take on challenging roles; encourage civic involvement and provide opportunities for youth to feel connected and valued (Martin, \& Tennant, 2008).

Having a sense of community represents a social economy of shared intimacy based on selfdisclosure and feelings (McMillan, 1996). This suggests that individuals who do not have a sense of community are at greater risk for feelings of social isolation and alienation, which may lead to experiences of loneliness and low self-esteem (Chipuer, 2001). An adolescent's feeling of connectedness to peers, parents, neighborhood and local communities are important to the developmental process and are predictors of a youth's self-esteem and ultimate life satisfaction (Barnett, \& Diehl, 2012). Youth may ultimately be empowered to become a critical component 
of the community development process and ultimately be engaged in the local policy planning, implementation, and evaluation as equal players (Barnett, \& Brennan, 2006).

\section{Methods}

\section{Research Design}

The study employed a quasi-experimental design which has the purpose of establishing a cause and effect relationship between an independent variable and a dependent variable, but the assignment of subject to treatment conditions is not at random (Cook, \& Campbell, 1979). This study specifically examined whether a program or treatment caused some outcome or outcomes to occur by examining the relationship of key variables. Adolescents were not randomly selected but were chosen based on their participation in an afterschool program. Quasi-experimental designs do determine the relationship between two or more variables as well as the direction of the relationship between the variables. For this study, the independent variable was Adolescent self-esteem and the two dependent variables were a) Adolescent's feelings of community connectedness; and b) Adolescent's afterschool program attendance.

\section{Data Collection}

For each of the two county afterschool program sites, a time was coordinated with the program director to come to the program and collect the data. All students present on the day of collection were asked to participate in the data collection process. Afterschool program participants were reminded that their participation was voluntary and that their responses would remain confidential and anonymous by placing a number on their survey rather than their name. At the time the data was collected, there were 61 students enrolled in the after school program. All youth participated in all or part of the study, but 22 of the 61 responses were not used for data analysis due to incomplete measures of program attendance maintained by staff on site. A total of 39 participants out of 61 enrolled students (63.9\%) including 17 males, (43.6\%), 21 females (53.8\%), and one unidentified sex (2.6\%) participated in the study. The ages of the 39 youth participants in the study ranged from 11-18. As follows: ages 11-four youth $(10.2 \%) ; 12-12$ youth (30.8\%); 13-eight youth $(20.5 \%) ; 14$-seven youth $(17.9 \%), 15-$ three youth $(7.7 \%), 16$-three youth $(7.7 \%) ; 18$-one youth $(2.6 \%)$; and unidentified age- one youth (2.6\%). Respondent's race was identified as follows: African American-29 youth (74.4\%), Hispanic/Latino-six youth (15.4\%); Caucasian-two youth (5.1\%); and unidentified race-two youth $(5.1 \%)$.

Self-esteem was measured using the Rosenberg's (1965) 10-item Self-esteem Scale which consists of statements dealing with general feelings about the self. The complete scale took about 10 minutes for completion and proved to be a reliable measure of self-esteem with a Cronbach's Alpha score of .758. The questionnaire consisted of the following conceptual areas: a). Self-worth; b). Success or failure; c). Ability; and d). Attitude. Each item consisted of answers ranging from 0 , "strongly agree" to 3, and "strongly disagree". Some items were reverse coded so that 3 represented "strongly agree" and 0 "strongly disagree". The raw score was measured and ranged from one the lowest level of self-esteem to 30 the highest level of self-esteem. Those with low levels of self-esteem were designated as having self-esteem scores that ranged from 0-10 and were assigned to group 1; mid range self-esteem scores ranged from 11-20 and were assigned to group 2; and a high level self-esteem score was classified as 21-30 and assigned to group 3.

To assess adolescent perceptions/feelings of community connectedness, a 5-item index measure of the variable was taken from the Youth Involved in Community Issues Survey (YICI) 
(Barnett, \& Payne, 2010). The community connectedness scale took approximately five minutes to complete. The 5-item survey measured community connectedness on a five point scale ranging from 1 , strongly disagree to 5 , strongly agree. The YICI survey was administered to all 39 participants in the afterschool program study in June 2011. The following five YICI survey items measured perceptions of community connectedness: a). Youth in my community have a voice; b). I feel connected to my community; c). I am not interested in what goes on in my community; d). I am able to influence decisions that affect my community; and e). I do not feel I have a positive impact on my community (Barnett, \& Payne, 2010).

These questions allowed the researcher to determine whether or not the adolescent's felt as though they were valued in the community and whether they were willing to go into the community and make decisions. The measure of perceptions/feelings of community connectedness ranged from 5-25. Those reporting low feelings of community connectedness were identified with a score of 5-11 and were assigned to group 1 . Those with mid level feelings of community connectedness were those with a score of 12-18 and were assigned to group 2, and those reporting high feelings of community connectedness were those with scores of $19-25$ and were assigned to group 3 .

\section{Data Analysis/Results}

Data analysis was performed using SPSS 20.0, a statistical software program for social science research. For this analysis, Pearson Parametric correlations were used and found that a relationship between the variables did exist. Although most of the variables did not prove to have a strong positive relationship, they did exhibit a positive relationship with increased feelings of self-esteem and increased afterschool program attendance relating to increased feelings of community connectedness. In other words, as self-esteem of youth and their attendance in the program went up, their feelings of community connectedness also moved in a positive direction. There were a number of inter-item correlations between the items asked of participants in the study that provide further insights into their perceptions of the two variables, self-esteem and community connectedness (See Table One). 
Table 1

Self-esteem and community connectedness Pearson Correlation

\begin{tabular}{|c|c|c|c|c|c|c|}
\hline & $\begin{array}{l}\text { Youth in } \\
\text { my } \\
\text { community } \\
\text { have a } \\
\text { voice. }\end{array}$ & $\begin{array}{l}\text { I feel } \\
\text { connected } \\
\text { to my } \\
\text { community. }\end{array}$ & $\begin{array}{l}\text { I am not } \\
\text { interested } \\
\text { in what } \\
\text { goes on in } \\
\text { my } \\
\text { community. }\end{array}$ & $\begin{array}{l}\text { I am able } \\
\text { to influence } \\
\text { decisions } \\
\text { that affect } \\
\text { my } \\
\text { community. }\end{array}$ & $\begin{array}{l}\text { I do not feel } \\
\text { I have a } \\
\text { positive } \\
\text { impact on } \\
\text { my } \\
\text { community. }\end{array}$ & $\begin{array}{l}\text { Total } \\
\text { Community } \\
\text { Connected- } \\
\text { ness. }\end{array}$ \\
\hline $\begin{array}{l}\text { On the whole I am satisfied } \\
\text { with myself. } \\
\text { Pearson Correlation } \\
\text { Sig. (2-Tailed) }\end{array}$ & $\begin{array}{r}-.262 \\
.107\end{array}$ & $\begin{array}{r}. .107 \\
.517\end{array}$ & $\begin{array}{r}.054 \\
.743\end{array}$ & $\begin{array}{r}-.075 \\
.651\end{array}$ & $\begin{array}{l}.097 \\
.557\end{array}$ & $\begin{array}{r}. .151 \\
.358\end{array}$ \\
\hline $\begin{array}{l}\text { At times, I think I am no } \\
\text { good at all. } \\
\text { Pearson Correlation } \\
\text { Sig. (2-Tailed) }\end{array}$ & $\begin{array}{r}-.172 \\
.294\end{array}$ & $\begin{array}{l}.015 \\
.926\end{array}$ & $\begin{array}{l}.208 \\
.203\end{array}$ & $\begin{array}{l}.065 \\
.694 \\
\end{array}$ & $\begin{array}{l}.074 \\
.654\end{array}$ & $\begin{array}{l}.097 \\
.556\end{array}$ \\
\hline $\begin{array}{l}\text { I feel that I have a number } \\
\text { of good qualities. } \\
\text { Pearson Correlation } \\
\text { Sig. (2-Tailed) }\end{array}$ & $\begin{array}{r}-.200 \\
.221 \\
\end{array}$ & $\begin{array}{r}-.053 \\
.748 \\
\end{array}$ & $\begin{array}{l}.232 \\
.156 \\
\end{array}$ & $\begin{array}{l}.005 \\
.976 \\
\end{array}$ & $\begin{array}{l}.131 \\
.427 \\
\end{array}$ & $\begin{array}{l}.074 \\
.656 \\
\end{array}$ \\
\hline $\begin{array}{l}\text { I am able to do things as } \\
\text { well as most other people. } \\
\text { Pearson Correlation } \\
\text { Sig. (2-Tailed) }\end{array}$ & $\begin{array}{r}-.201 \\
.221 \\
\end{array}$ & $\begin{array}{r}-.036 \\
.830 \\
\end{array}$ & $\begin{array}{l}.077 \\
.639 \\
\end{array}$ & $\begin{array}{r}-.014 \\
.933 \\
\end{array}$ & $\begin{array}{l}.048 \\
.772 \\
\end{array}$ & $\begin{array}{r}-.038 \\
.820 \\
\end{array}$ \\
\hline $\begin{array}{l}\text { I feel I do not have much to } \\
\text { be proud of. } \\
\text { Pearson Correlation } \\
\text { Sig. (2-Tailed) }\end{array}$ & $\begin{array}{r}-.226 \\
.166 \\
\end{array}$ & $\begin{array}{l}.000 \\
1.00 \\
\end{array}$ & $\begin{array}{l}.158 \\
.336\end{array}$ & $\begin{array}{r}-.103 \\
.538 \\
\end{array}$ & $\begin{array}{l}.125 \\
.447\end{array}$ & $\begin{array}{l}.000 \\
1.00 \\
\end{array}$ \\
\hline $\begin{array}{l}\text { I certainly feel useless at } \\
\text { times. } \\
\text { Pearson Correlation } \\
\text { Sig. (2-Tailed) }\end{array}$ & $\begin{array}{c}-.332 * \\
.042\end{array}$ & $\begin{array}{r}-.142 \\
.395\end{array}$ & $\begin{array}{l}.281 \\
.088\end{array}$ & $\begin{array}{r}-.099 \\
.553\end{array}$ & $\begin{array}{l}.163 \\
.328\end{array}$ & $\begin{array}{r}-.018 \\
.914\end{array}$ \\
\hline $\begin{array}{l}\text { I feel that I'm a person of } \\
\text { worth, at least on an equal } \\
\text { plane with others. } \\
\text { Pearson Correlation } \\
\text { Sig. (2-Tailed) }\end{array}$ & $\begin{array}{l}.152 \\
.355\end{array}$ & $\begin{array}{l}.207 \\
.207\end{array}$ & $\begin{array}{l}.030 \\
.854\end{array}$ & $\begin{array}{l}.126 \\
.443\end{array}$ & $\begin{array}{r}-.035 \\
.831\end{array}$ & $\begin{array}{l}.183 \\
.265\end{array}$ \\
\hline $\begin{array}{l}\text { I wish I could have more } \\
\text { respect for myself. } \\
\text { Pearson Correlation } \\
\text { Sig. (2-Tailed) }\end{array}$ & $\begin{array}{l}-.455^{*} \\
.004\end{array}$ & $\begin{array}{c}-.445^{*} \\
.005\end{array}$ & $\begin{array}{l}.177 \\
.281 \\
\end{array}$ & $\begin{array}{r}-.240 \\
.142 \\
\end{array}$ & $\begin{array}{l}.272 \\
.094 \\
\end{array}$ & $\begin{array}{r}.227 \\
.164 \\
\end{array}$ \\
\hline $\begin{array}{l}\text { All in all, I am inclined to feel } \\
\text { that I am a failure. } \\
\text { Pearson Correlation } \\
\text { Sig. (2-Tailed) }\end{array}$ & $\begin{array}{r}-.256 \\
.115\end{array}$ & $\begin{array}{r}-.139 \\
.400\end{array}$ & $\begin{array}{l}.374 * \\
.019\end{array}$ & $\begin{array}{r}-.259 \\
.111 \\
\end{array}$ & $\begin{array}{l}.335^{*} \\
.037\end{array}$ & $\begin{array}{l}.069 \\
.675 \\
\end{array}$ \\
\hline $\begin{array}{l}\text { I take a positive attitude } \\
\text { toward myself. } \\
\text { Pearson Correlation } \\
\text { Sig. ( } 2 \text {-Tailed) }\end{array}$ & $\begin{array}{r}-.230 \\
.158\end{array}$ & $\begin{array}{r}-.129 \\
.434\end{array}$ & $\begin{array}{l}.115 \\
.486\end{array}$ & $\begin{array}{r}-.155 \\
.346\end{array}$ & $\begin{array}{l}.145 \\
.379\end{array}$ & $\begin{array}{r}-.080 \\
.627\end{array}$ \\
\hline $\begin{array}{l}\text { Total Self-Esteem } \\
\text { Pearson Correlation } \\
\text { Sig. (2-Tailed) }\end{array}$ & $\begin{array}{l}-.388^{*} \\
.015\end{array}$ & $\begin{array}{r}-.172 \\
.294\end{array}$ & $\begin{array}{l}.273 \\
.092\end{array}$ & $\begin{array}{r}.155 \\
.347\end{array}$ & $\begin{array}{l}.225 \\
.169\end{array}$ & $\begin{array}{r}-.046 \\
.781\end{array}$ \\
\hline
\end{tabular}

*Significant at $0.05 \quad * *$ Significant at 0.01

The research also found a significant relationship between self-esteem and community connectedness on seven different individual items. The individual item correlations proved to be more significant than the correlation found between total self-esteem and feelings of 
community connectedness. The researcher's hypothesized that an increase in afterschool program attendance would result in an adolescent's increased feelings of community connectedness. This hypothesis was accepted since the correlation between variables was significant with a Pearson Correlation score of .3578 and a significance score of .026. This finding is extremely important as it proves that there is a relationship between adolescent feelings of community connectedness and afterschool program attendance. The statistical analysis presented in this study has shown a correlation between the variables selected. There is a significant relationship evident between the individual items contained in each variable, specifically, in the relationship between self-esteem and feeling of connectedness to the community in which the participants live. Particularly alarming is the finding that amongst the participants in the survey, there was no correlation between afterschool program attendance and self-esteem. However, since it was a sample of convenience taken of students who already attend the program, some for more than a year, it could be possible that the afterschool program had already helped the students with their self-esteem and feelings of community connectedness. Pre- and post self-esteem and feelings of community connectedness measures may have possibly produced different findings than this study on the relationships between the existing level of self-esteem and the other variables.

\section{Discussion}

Adolescence is a developmental stage characterized by many corresponding changes, including those in physical, emotional, cognitive, social and moral domains. As youth experience these changes, they often have a decline in self-esteem related to their changing states of self (Arnett, 2010). Numerous factors have been proven to affect an adolescent's self-esteem, both negatively and positively. Through after school program attendance, the adolescent may not only become more resilient to changes going on around and inside them, but they may also have increased feelings of community connectedness.

Although afterschool program attendance was not proven to have a significant effect on an adolescent self-esteem, participants in this study reported higher levels of self-esteem than expected, which left little room for growth. Afterschool program attendance in previous studies has been proven to increase adolescent self-esteem, but in this study, a direct relationship cannot be determined. Still, there are some interesting findings from this study for practitioners to think about as they work with these more extreme populations in regard to risk.

For example, adolescent self-esteem and afterschool program attendance of those who participated in this study showed great variance in some areas (attendance) and very little variance in others (self-esteem). Although these results cannot be identified as causal, it is suggested through previous research that adolescents with higher self-esteem do attend afterschool programs. In this study, the relationship between the two is not definite as the adolescents in this particular program are given the choice of whether or not to attend. Therefore, it may not be the level of self-esteem that prompted them to attend or not attend the afterschool program. It is possible that the students not required by the program to attend were required by their parents to attend; thus, their self-esteem is perhaps not affecting that decision, their parents are possibly affecting it. Many of the program participants also attend as a recommendation by the school. Again, the decision to attend may not be directly influenced by their choice, but possibly by a higher authority.

Community connectedness is an important aspect of an impactful afterschool program. When an afterschool program has the ability to help youth connect to their community, the program is 
assisting the adolescent's development in many areas. Not only is the feeling of community connectedness beneficial to an adolescent's self-esteem, it also allows them to feel appreciated by the members of their community. This appreciation of adolescents allows the youth to begin to take ownership of their community as it becomes more meaningful to them and encourages them to want to contribute positively to it.

Specific items in this study correlated with one another that focus on the community connectedness aspect of the program and its' impact on their feelings about connectedness. For example, the item Youth have a voice in this community has a significant inverse relationship with the item I certainly feel useless at times and I wish I could have more respect for myself. This relationship indicates that as youth having a voice in the community increases, these negative feelings about themselves decreases. The relationship with total self-esteem, however, is more difficult to understand, but may be explained by the unusually high initial self-esteem scores that allow little room for increase, therefore, any changes that the adolescents report in self-esteem may actually show a decline in self-esteem. A significant inverse relationship was also found between the items I feel connected to my community and I wish I could have more respect for myself, which explains that as youth feel more connectedness to their greater environmental context, their need for more self-respect declines because self-respect is likely enhanced when their connectedness increases.

Conversely, and perhaps more importantly, youth reporting that $A / l$ in all, I am inclined to feel like a failure also has a significant inverse relationship with I do not feel I have a positive impact on my community, lending further evidence that empowering youth to have a voice about local community matters and is preventative in regard to these negative aspects of self. These interitem relationships provide evidence related to the impact of increasing community connectedness in afterschool programs for youth respective to development of their selfesteem. It is often beneficial to allow adolescents to have the ability to participate and volunteer to help with community events. This is a way for adolescents to have a greater presence in the community and have their voices heard by the community. Recognition by members of the community and the ability to help others in their area, whether it is the young or the old, will help adolescents develop a high self-esteem. This study shows that adolescents who feel as though they have a voice in their community will have more respect for themselves. Having more respect for oneself transcends across many areas of the adolescent's life and will help them to have more respect for everyone around them.

\section{Implications for Further Research}

For further research, self-esteem and feelings of community connectedness measures might be taken at least twice during the study. Collecting these two data sources twice rather than once will hopefully show variance in the scores that are collected and potentially find a relationship between the three variables: afterschool program attendance, self-esteem and feelings of community connectedness. Also, if measuring afterschool program attendance, it is imperative that proper record keeping is taking place. Afterschool program attendance has been identified as a variable in many studies, but would be best-suited if analyzed based on both frequency and consistency of attendance. Another suggestion for further research is to compare selfesteem and community connectedness measures on both adolescents who do not attend the afterschool program and those who do attend. This would hopefully show some variance between the two groups and indicate a stronger relationship between afterschool program attendance, self-esteem and feelings of community connectedness among those who attended programs as opposed to those youth who did not. 
In order to determine a relationship between self-esteem and feelings of community connectedness in further research, a larger sample size is also suggested. A sample that spans ethnic groups will potentially identify differences and similarities in areas not limited to the relationship between self-esteem and community connectedness, but also the relationship between age, race, self-esteem and feelings of community connectedness. The larger sample size would hopefully yield a range of scores from low to high in both self-esteem and community connectedness. This range of scores will allow for further examination of the relationships and presumably reveal that feelings of community connectedness and self-esteem are directly related.

These suggestions are made based on the limitations of this study that was conducted using a sample of at-risk youth enrolled in an afterschool program specifically focused on this population. The program was grant funded to provide a free afterschool program to disadvantaged youth considered to be very at-risk due to their SES level, the highly disorganized neighborhoods in which they lived, and the transitory nature of their migrant families. This study did not have access to a comparative or control group through the local school district; therefore, the participants were limited to those enrolled in the program. The study did have the opportunity, however, to focus on two very at-risk youth populations that might be considered extreme in contrast to the typical youth, as they are faced with very adverse circumstances.

\section{Practice}

For youth workers, the results of this study are particularly important. Self-esteem and feelings of community connectedness are extremely important to an adolescent's successful development into an adult who can thrive in any situation. After school programs must be places that bolster self-esteem and feelings of community connectedness in order to create resilient adolescents. For those youth workers engaged in providing supports to at-risk youth populations, this study has found evidence regarding the importance of making connections to the community for enhancing self-esteem for these particularly vulnerable populations. It is not known, however, why these youth reported such high self-esteem scores, but it is hoped that the program had already had a substantial impact on their development of self, as some of the youth had been enrolled in the program for one year at the time of the data collection, therefore, the baseline measure may have already been raised higher for these youth. In order to bolster adolescent self-esteem and feelings of community connectedness, it is important to get the adolescents out in the community in which they live so that they are able to elicit change and feel as though they are a contributing member of the community, instead of a mere resident. For adolescent's voices to be heard in the community, afterschool programs could hold community outreach events where the adolescents showcase talents and skills that they have learned while attending the afterschool program.

When adolescents begin to feel as though they have a voice in their community, according to these findings, they will begin to feel greater respect for themselves. With greater feelings of respect for themselves, heightened self-esteem and greater feelings of community connectedness will follow. If possible, afterschool programs should have their participants sign a contract saying that they will regularly attend the program. Of course the parent will make the final decision, but if the adolescent feels as though they are valued and are given the opportunity to make decisions for themselves, great growth will occur. 


\section{Program Staff}

For the staff of this afterschool program and afterschool programs like it, it is important that they use this research to make the necessary changes that the adolescents who attend the program desire. Specifically, adolescents need to be given a voice in what goes on not only in the program, but in the community as well. In order for adolescents to feel confident enough to let their voice be heard in the community, they must begin by being given an equal voice in the program thus allowing them to be seen as an asset. What this translates to in the application of these findings is that the program leaders and facilitators will give the adolescent the opportunity to make decisions about what goes on at the program. In doing this, the youth will not only begin to enjoy the program even more, but it may also give the program the opportunity to grow through word of mouth and community outreach, all the while building connections between the youth, the program, and the community that they live in

\section{Summary}

The results of the study found that there was a significant relationship between an adolescent's afterschool program attendance and self-esteem or feelings of community connectedness among the adolescents who attended the federally funded afterschool program. Although no direct correlation was found between an adolescent's self-esteem and feelings of community connectedness, correlation was found between individual items. Most importantly, adolescents felt that they could have greater respect for themselves if they had a voice in their community. This is significant because the adolescent's clearly feel as though they would respect themselves more if others also respected them.

The results of this study can be used to develop programs that allow adolescents to participate in community outreach events that allow them to have their voices heard. This will allow adolescents to take ownership of their community while developing a greater respect for themselves, their community, and the people in it. This can become the focus of afterschool programs that are community based and infuse self-esteem building activities. As youth workers strive to create effective youth programs, they can consider the findings of this study that provide evidence that afterschool programs and community connectedness do have an impact on an adolescent's self-esteem and positive identity development.

\section{References}

Arnett, J. (2010). Adolescence and emerging adulthood. (4 ${ }^{\text {th }}$ ed.). Upper Saddle River, NJ: Pearson.

Barnett, R.V., \& Brennan, M.A. (2006). Integrating youth into community development: Implications for policy planning and program evaluation. Journal of Youth Development, Volume 1; Issue 2.

Barnett, R.V., \& Diehl, D. (2012). An ecological examination of developmental assets to aid retention of rural youth in agriculturally relevant communities (In review.)

Barnett, R.V., \& Payne, C.M. (2010). Youth involved in community issues survey (YICI). Gainesville, FL: University of Florida. 
Barton, W.H., Watkins, M., \& Jarjoura, R. (1997). Youth and communities: Toward comprehensive strategies for youth development. Social Work (42) 5: pp. 483-493.

Benson, P. (1998). Mobilizing communities to promote developmental assets: A promising strategy for prevention of high-risk behaviors. Family Science Review 11, pp. 220-238.

Broadbent, R., \& Papadopoulos, T. (2010). Government, schools, young people and communities in partnership. Youth Studies Australia 29 (3), pp. 52-60.

Chipuer, H.M. (2001). Dyadic attachments and community connectedness: Links with youths' loneliness experiences. Journal of Community Psychology, 29 (4), pp. 429-446.

Cook, T.D., \& Campbell, D.T. (1979). Quasi-experimentation: Design and analysis issues for field settings. Boston, MA: Houghton Mifflin.

Erickson, E.H. (1950). Childhood and society. New York, NY: Norton

Halpern, R. (2005). Instrumental relationships: A potential relational model for inner-city youth programs. Journal of Community Psychology 33 (1), pp. 11-20.

Hornbeck, D.W. (1988). "Values Education and Student Government Service." Address to Community Service Conference. Council of Chief State School Officers, Baltimore, MD, April. 1988.

Martin, D., \& Tennant, G. (2008). Child and youth care in the community centre. Relational Child and Youth Care Practice 21(2), pp. 20-26.

Matlin, S., Molock, S.D., Tebes, J.K. (2011). Suicidality and depression among African American adolescents: The role of family and peer support and community connectedness. American Journal of Orthopsychiatry 81(1), 108-117.

McMillan, D.M. (1996). Sense of community. Journal of Community Psychology, 24, pp. 315325.

O'Donnell, J., Michalak, E.A., \& Ames, E.B. (1997). Inner city youths helping children's afterschool programs to promote bonding and reduce risk. Social Work in Education 19 (4), pp. $231-241$.

Rosenberg, M. (1965). Society and the adolescent self-image. Princeton, NJ: Princeton University Press.

Saunders-Ferguson, K., Barnett, R.V., Culen, G., \& TenBroeck, S. (2008). Self-esteem of adolescents involved in horsemanship activities. Journal of Extension 46 (2), 9 pages.

Schine, J. (1990). A rationale for youth community service. Social Policy 20 (4), pp. 5-11. Search Institute. (2007). The 40 developmental assets for adolescents. Retrieved from http://www.search-institute.org/assets/

Ybrandt, H., \& Armelius, K. (2010). Peer aggression and mental health problems: Self-esteem as a mediator. School Psychology International 31, pp. 146-160. 
(C) Copyright of Journal of Youth Development Bridging Research and Practice. Content may not be copied or emailed to multiple sites or posted to a listserv without copyright holder's express written permission. However, users may print, download or email articles for individual use. 